\title{
Results of Intravitreal Bevacizumab as an Adjunct to mETDRS Grid Laser in Diabetic Macular Edema
}

\author{
Mahtab Alam Khanzada ${ }^{1}$, Munawar Ahmed², Azfar Ahmed Mirza ${ }^{3}$, Ghazi Khan Mari ${ }^{4}$, Muhammad \\ Arshad Mahmood ${ }^{5}$ \\ ${ }^{1-4}$ Department of Ophthalmology, Liaquat University of Medical \& Health Sciences, Jamshoro, ${ }^{5}$ Department of \\ Ophthalmology, Gulab Devi Teaching Hospital, Lahore
}

\begin{abstract}
Purpose: To assess the efficacy of Intravitreal Bevacizumab as an adjuvant to grid laser photocoagulation in patients with diffuse macular edema (DME) in type II diabetes.
\end{abstract}

Study Design: Quasi experimental study.

Place and Duration of Study: Institute of Ophthalmology, Liaquat University of Medical and Health Sciences, Jamshoro, from September 2016 to November 2018.

Methods: Ninety-five type II diabetic patients with diffuse macular edema were selected by convenient sampling. Group I patients were treated with ETDRS grid laser photocoagulation. Group II patients were treated with ETDRS grid laser photocoagulation followed by intravitreal bevacizumab after one week monthly for 2 months and then as per need. All patients were examined after $1^{\text {st }}, 2^{\text {nd }}$ and $3^{\text {rd }}$ month and mean change in best corrected visual acuity (BCVA) and central macular thickness (CMT) was recorded.

Results: The results of study were compared with the baseline values. The mean change in BCVA in group 1 was from $46 \pm 18$ letters to $52 \pm 17$ letters and in group 2 was from $46 \pm 18$ letters to $56 \pm 17$ letters $(P<0.001)$. Mean base line CMT was $504 \mu \mathrm{m}(\mathrm{SD} \pm 189)$ in $\mathrm{G}-\mathrm{I}$ and $506 \mu \mathrm{m}(\mathrm{SD} \pm 189)$ in G-II. Mean CMT reduction was statistically significant in both groups during all follow up visits but in G-I it was $194 \mu \mathrm{m}$ ( $\leq \leq 0.001)$ and in G-II 272 $\mu \mathrm{m}(\mathrm{p} \leq 0.001)$ at 6 months.

Conclusion: Macular Grid laser with or without Intravitreal Bevacizumab significantly improves vision and decreases macular edema but combined treatment led to more stable improvement in DME during follow-up.

Key Words: Grid laser, Bevacizumab, Macular edema, Anti-VEGF.

How to Cite this Article: Khanzada MA, Ahmed M, Mirza AA, Mari GK, Mahmood MA Results of Intravitreal Bevacizumab as an Adjunct to mETDRS Grid Laser in Diabetic Macular Edema. Pak J Ophthalmol. 2021,37 (1): 12-16.

Doi: https://doi.org/10.36351/pjo.v37i1.1135

\section{INTRODUCTION}

According to International Diabetic Federation report published in 2017 there are four hundred and fifty-one

Correspondence: Munawar Ahmed

Department of Ophthalmology, Liaquat University of Medical \& Health Sciences, Jamshoro

Email: munawar_404@yahoo.com

Received: September 9, 2020

Accepted: October 9, 2020 million people in the world who have diabetic mellitus. By the year 2045 this figure may reach up to six hundred and ninety-three and half of them do not know about the disease. ${ }^{1}$ Worldwide the leading cause of visual impairment in working age group population is diabetic macular edema (DME) which is another worse manifestation of diabetic retinopathy. ${ }^{2}$

There are so many different strategies to treat diabetic macular edema (DME) but medical management of systemic risk factors should be optimized before any treatment. Otherwise, it may 
remain insufficient to control the progression of the disease and prevent recurrence of ocular complications. ${ }^{3}$ Different patients have different response to the treatment of DME. Therefore, we should adopt such strategies which give good results and have less side effects. ${ }^{4}$ For the management of DME laser photocoagulation was the best option few decades back. It was established by Early treatment of Diabetic Retinopathy Study (ETDRS) in 1980s. ${ }^{4}$ Nowadays intravitreal injection of anti-vascular endothelial growth factor (AVEGF) is more popular than laser due to easy administration and early recovery of vision. ${ }^{3}$ But a research conducted by Diabetic Retinopathy Clinical Research Network (DRCR.net) stated that modified ETDRS (mETDRS) protocol to treat DME was the best approach ${ }^{5}$ and protocol $\mathrm{T}$ clinical trial showed that $50 \%$ patients with DME required additional laser therapy within sixth months after injection of anti-VEGF. ${ }^{6}$ It means laser photocoagulation still has a role to treat DME but laser and anti-VEGF both have their own efficacy and visual outcomes. Macular laser therapy is a good treatment option as an adjuvant because it is able to improve macular thickness outcomes and reduce the number of injections needed.

In this study, anti-VEGF was used as an adjunct to laser photocoagulation in patients with DME to get early vision recovery and to decrease the financial burden on the society. The purpose of the study was to assess the efficacy of Intravitreal Bevacizumab as an adjuvant to grid laser photocoagulation in patients with diffuse macular edema (DME) in type II diabetes.

\section{METHODS}

Ninety-five eyes of type II diabetic patients, with diffuse macular edema (48 males and 47 females) were recruited for this prospective study, from the outpatient clinic of Institute of Ophthalmology Liaquat University of Medical and Health Sciences Jamshoro. The duration of study was from September 2016 to November 2018 after approval from Ethics Committee of the University. Written informed consent was obtained from all participating patients after explaining to them all the study procedures with its benefits and hazards.

Patients older than 40 years with macular edema caused by type II Diabetes, BCVA of $6 / 18$ to $6 / 60$, central macular thickness (CMT) more than $300 \mu \mathrm{m}$, intra ocular pressure less than $20 \mathrm{~mm} \mathrm{Hg}$, clear optical zone with properly dilated pupils and no iris neovascularization were included in the study. Patients who had diabetic macular edema (DME) with subfoveal exudates, macular edema caused by diseases other than DM, macular ischemia \& traction, CMT greater than $1000 \mathrm{um}$, preexisting macular pathology, history of $(\mathrm{H} / \mathrm{O})$ intravitreal injection/vitrectomy, $\mathrm{H} / \mathrm{O}$ cataract surgery within the past 6 months and $\mathrm{H} / \mathrm{O}$ renal pathology, glaucoma/ocular hypertension, HbA1c more than $8 \%$, blood pressure more than $150 / 90 \mathrm{~mm} \mathrm{Hg}$ and significant media opacity were excluded from the study.

All patients who fulfilled the inclusion criteria were subjected to clinical examination and base line BCVA was recorded by Snellen Chart, intra ocular pressure (IOP) was recorded using applanation tonometer with slit lamp biomicroscope and colored fundus photograph and CMT was taken with SD-OCT. All patients were divided in two groups Group I patients were treated with ETDRS grid laser photocoagulation. Group II patients were treated with ETDRS grid laser photocoagulation combined with intravitreal bevacizumab $(1.25 \mathrm{mg} / 0.05 \mathrm{ml})$. All patients were examined at baseline and followed-up at 1,2 and 3 months after treatment. Changes in BCVA were recorded with Snellen acuity chart \& converted into ETDRS letter for facilitating statistical calculation. Intravitreal injections of anti-VEGF were performed with aseptic technique and post injection Moxifloxacin 3\% one drop four times a day and post laser non-steroidal anti-inflammatory one drop three times a day was advised. Combination of acetazolamide and timolol one drop twice a day was advised in patients with raised IOP.

Macular grid photocoagulation was performed with argon green laser delivering 2-3 rows using mETDRS grid Laser parameters for DME. Burn size for grid was $75 \mu \mathrm{m}$, burn duration was $0.05-0.10 \mathrm{~s}$, burn separation was 2 visible burn widths apart and burn intensity was light gray

Descriptive analysis of subjects like mean, standard deviation and range was performed by using SPSS version 20. Mean change in VA and CMT was estimated with paired t-test. The level of statistical significance was set at $\mathrm{P}<0.05$. Changes in BCVA were recorded with Snellen acuity chart and converted into ETDRS letters for facilitating statistical calculation. 


\section{RESULTS}

The demographic and base line clinical characteristics are listed in Table I. The mean age of G-1 group patients was 59.45 ( $\mathrm{SD} \pm 8.23$ ) years and of G-2

Table 1: Baseline demographic and clinical characteristics of each group of study patients

\begin{tabular}{lcc}
\hline Characteristics & Group-1 & Group-2 \\
\hline Age (years) & $59.45 \pm 8.23$ & $60.11 \pm 7.36$ \\
Male, $n(\%)$ & $25(26.31 \%)$ & $23(24.21 \%)$ \\
Female, $n(\%)$ & $22(23.15 \%)$ & $25(26.31 \%)$ \\
Disease duration (year) & $11.10 \pm 2.42$ & $12.48 \pm 2.91$ \\
HbA1c $(\%)$ & $07.85 \pm 0.78$ & $07.96 \pm 0.76$ \\
IOP $(\mathrm{mmHg})$ & $17.68 \pm 2.49$ & $18.20 \pm 3.19$ \\
Blood pressure (mm Hg) & & \\
Systole & $145 \pm 17.11$ & $138 \pm 15.90$ \\
Diastole & $85 \pm 8.10$ & $83 \pm 8.10$ \\
CMT $(\mu \mathrm{m})$ & $504 \pm 189$ & $507 \pm 189$ \\
\hline
\end{tabular}

patients was $60.11(\mathrm{SD} \pm 7.36)$ years. Out of ninetyfive patients, 25 (26.31\%) males and 22 (23.15\%) females were treated with mETDRS grid laser photocoagulation and $23(24.21 \%)$ male and 25 $(26.31 \%)$ females were subjected to combined treatment.

BCVA ranged from 4 to 76 letters (Snellen equivalent $1 / 60$ to 6/9). Eyes with poor base line BCVA achieved greatest mean improvement at 6 months (Table 2). Mean base line CMT was $504 \mu \mathrm{m}$ $(\mathrm{SD} \pm 189)$ in G-I and $506 \mu \mathrm{m}(\mathrm{SD} \pm 189)$ in G-II. Mean CMT reduction was statistically significant in both groups during all follow up visits but in G-I it was $194 \mu \mathrm{m}(\mathrm{p} \leq 0.001)$ and in G-II $272 \mu \mathrm{m}$ $(\mathrm{p} \leq 0.001)$ at 6 months. Only $0.045 \%$ patients of $\mathrm{G}-2$ were found with raised IOP that was controlled by anti-glaucoma drops.

Table 2: Change in Base line BCVA \& CMT.

\begin{tabular}{|c|c|c|c|c|c|}
\hline $\begin{array}{l}\text { Subject } \\
\text { (ETDRS Letter Score) }\end{array}$ & & Mean BCVA (letters) & P-Value & Mean CMT $(\mu \mathrm{m})$ & P-Value \\
\hline Baseline & $\begin{array}{l}\text { Baseline } \\
\text { G-1 }(n=47) \\
\text { G-2 }(n=48)\end{array}$ & $\begin{array}{l}46 \pm 18 \\
46 \pm 18\end{array}$ & & $\begin{array}{l}504 \pm 189 \\
507 \pm 189\end{array}$ & \\
\hline $1^{\text {st }}$ Months PT & $\begin{array}{l}\mathbf{1}^{\text {st }} \text { Months PT } \\
\text { G-1 }(\mathrm{n}=47) \\
\text { G-2 }(\mathrm{n}=48)\end{array}$ & $\begin{array}{l}47 \pm 21 \\
48 \pm 21\end{array}$ & $\begin{array}{c}0.912 \\
0.801\end{array}$ & $\begin{array}{l}365 \pm 143 \\
350 \pm 157\end{array}$ & $\begin{array}{l}0.018 \\
0.004\end{array}$ \\
\hline $2^{\text {nd }}$ Months PT & $\begin{array}{l}2^{\text {nd }} \text { Months PT } \\
\text { G-1 }(\mathrm{n}=47) \\
\text { G-2 }(\mathrm{n}=48)\end{array}$ & $\begin{array}{l}50 \pm 17 \\
53 \pm 17\end{array}$ & $\begin{array}{l}0.021 \\
0.009\end{array}$ & $\begin{array}{l}350 \pm 150 \\
322 \pm 160\end{array}$ & $\begin{array}{l}0.001 \\
0.002\end{array}$ \\
\hline $3^{\text {rd }}$ Months PT & $\begin{array}{l}\mathbf{3}^{\text {rd }} \text { Months PT } \\
\text { G-1 }(\mathrm{n}=47) \\
\text { G-2 }(\mathrm{n}=48)\end{array}$ & $\begin{array}{l}52 \pm 17 \\
56 \pm 17\end{array}$ & $\begin{array}{l}0.004 \\
0.004\end{array}$ & $\begin{array}{l}310 \pm 130 \\
235 \pm 128 \\
\end{array}$ & $\begin{array}{l}0.001 \\
0.001\end{array}$ \\
\hline
\end{tabular}

G-1 = Group I, G-2 = Group II, PT = Post treatment, BCVA = best corrected visual acuity, CMT = Central macular thickness ETDRS $=$ Early treatment of Diabetic Retinopathy Study, SD = Stander deviation

\section{DISCUSSION}

Prevalence of DME is approximately $19 \%$ to $65 \%$ and it is the main cause of severe loss of vision among patients with diabetes mellitus. ${ }^{7}$ Pathogenesis of DME is multi factorial like: angiogenesis, inflammation and oxidative stress. ${ }^{8,9}$ Therefore, a single treatment option does not show adequate response especially in diffuse, chronic and refractory DME. Various variants of VEGF increase vascular permeability by increasing phosphorylation of endothelial tight junction proteins in diabetes mellitus that may lead to DME. ${ }^{10}$ Another proposed reason of DME is the breakdown of outer and inner retinal barrier. ${ }^{11}$ Solaiman et al ${ }^{12}$ suggested that the laser photocoagulation causes proliferation of endothelial cells in the retinal capillaries as well as retinal pigment epithelial cells thus improving the functions of outer and inner retinal barriers. Bevacizumab has the ability to block all form of VEGF receptors. This stabilizes the vascular permeability and helps to reduce DME. ${ }^{13}$ Since last three-decades conventional ETDRS laser photocoagulation was standard treatment for DME but results of visual outcome were modest. ${ }^{14,15}$ Visual acuity may decrease due to extension of macular scar, 
and patients may suffer central scotoma and altered color vision. ${ }^{16}$ To avoid these complications, we used mETDRS laser treatment in this study.

As we compare the base line during each visit, we found significant reduction in CMT in both groups during each follow-up visit but at 6 months it was stable and more significant in combined group ( $\mathrm{p} \leq$ 0.001). At 6 months, visual acuity letters gain was more significant in combined group than laser group.

Our results are in consistence with previous studies which reported that the combined intravitreal Bevacizumab (IVB) and laser photocoagulation was the best option not only to treat DME but also to help in decreasing the chance of recurrence. ${ }^{17,18}$ Shalaby et $\mathrm{al}^{19}$ reported that combined intravitreal anti VEGF and mETDRS laser had more stable functional and anatomical out comes after treating DME. We also had the same results but difference was that we applied laser before injecting IVB.

Other studies have also reported that combined treatment was more effective in treating DME than conventional macular laser photocoagulation. Adelman et $\mathrm{al}^{20}$, and Do et $\mathrm{al}^{21}$ stated that by adding macular laser photocoagulation with IVB to treat DME may not give significant results and more extensive laser treatment may help to reduce the number of intravitreal anti-VEGF injection. That is why in this study we did first grid laser photocoagulation before injecting IVB to reduce the burden of injection to patients.

\section{Ethical Approval}

The study was approved by the Institutional review board/ Ethical review board. (LUMHS/04)

\section{Conflict of Interest}

Authors declared no conflict of interest

\section{REFERENCES}

1. Cho NH, Shaw JE, Karuranga S, Huang Y, da Rocha Fernandes JD, Ohlrogge AW, et al. IDF Diabetes Atlas: Global estimates of diabetes prevalence for 2017 and projections for 2045. Diabetes Res Clin Pract. 2018; 138: 271-278.

2. Stefanini FR, Badaró E, Falabella P, Koss M, Farah ME, Maia M. Anti-VEGF for the Management of Diabetic Macular Edema. J Immun Res. 2014: 1-8.
3. Marashi A. Laser therapy for diabetic retinopathy and diabetic macular edema Laser still plays an important role in the treatment of diabetic eye disease, despite the popularity of anti-VEGF agents. Retina Today, 2017: 38-42.

4. Stanga PE, Martinez MG, Pastor-Iodate S. New Laser Technology and Techniques for Treating DME and PDR. Supplement to Retina Today. 2013: 6-8.

5. Fong DS, Strauber SF, Aiello LP, Beck RW, Callanan DG, Danis RP, et al. Comparison of the modified Early Treatment Diabetic Retinopathy Study and mild macular grid laser photocoagulation strategies for diabetic macular edema. Arch Ophthalmol. 2007; 125: $469-480$.

6. Wells JA, Glassman AR, Ayala AR, Jampol LM, Bressler NM, Bressler SB, et al. Aflibercept, Bevacizumab, or Ranibizumab for diabetic macular edema: two-year results from a comparative effectiveness randomized clinical trial. Ophthalmology, 2016; 123: 1351-1359.

7. Virgili G, Menchini F, Murro V, Peluso E, Rosa F, Casazza G, et al. Optical coherence tomography (OCT) for detection of macular oedema in patients with diabetic retinopathy," Cochrane Database of Syst Rev. Cochrane Database Syst Rev. 2011; 7: CD008081.

8. Ehrlich R, Harris A, Ciulla TA, Kheradiya N, Winston DM, Wirostko B. Diabetic macular oedema: physical, physiological and molecular factors contribute to this pathological process. Acta Ophthalmol. 2010; 88 (3): 279-291.

9. Tang J, Kern TS. Inflammation in diabetic retinopathy. Prog Retin Eye Res. 2011; 30 (5): 343358.

10. Ferrara N. Vascular endothelial growth factor: Basic science and clinical progress. Endocr Rev. 2004; 25: 581-611.

11. Mohalhal AA, Ghalwash GA. Short-term effect of a single intravitreal injection of bevacizumab (Avastin) alone, triamcinolone alone, or in combination, followed by macular grid laser photocoagulation on diffuse diabetic macular edema. J Egypt Ophthalmol Soc. 2014; 107: 127-131.

12. Solaiman KA, Diab MM, Dabour SA. Repeated intravitreal bevacizumab injection with and without macular grid photocoagulation for treatment of diffuse diabetic macular edema. Retina. 2013; 33: 1623-1629.

13. Soheilian M, Ramezani A, Obudi A, Bijanzadeh B, Salehipour M, Yaseri M, et al. Randomized trial of intravitreal bevacizumab alone or combined with triamcinolone versus macular photocoagulation in diabetic macular edema. Ophthalmology, 2009; 116: 1142-1150. 
14. Elman MJ, Aiello LP, Beck RW, Bressler NM, Bressler SB, Edwards AR, et al. Diabetic Retinopathy Clinical Research Network. Randomized trial evaluating ranibizumab plus prompt or deferred laser or triamcinolone plus prompt laser for diabetic macular edema. Ophthalmology, 2010; 117 (6): 1064-1077.

15. Heng LZ, Comyn O, Peto T, Tadros C, Ng E, Sivaprasad S, et al. Diabetic retinopathy: pathogenesis, clinical grading, management and future developments. Diabet Med. 2013; 30 (6): 640-650.

16. Roider J. Laser treatment of retinal diseases by subthreshold laser effects. Semin Ophthalmol. 1999; 14: 19-26.

17. Seo JW, Park IW. Intravitreal bevacizumab for treatment of diabetic macular edema. Korean $\mathrm{J}$ Ophthalmol. 2009; 23: 17-22.

18. Zhang XL, Chen J, Zhang RJ, Wang WJ, Zhou Q, Qin XY, et al. Intravitreal triamcinolone versus intravitreal bevacizumab for diabetic macular edema: A meta-analysis. Int J Ophthalmol. 2013; 6: 546-552.

19. Shalaby UA, Soliman TT, El-Hameed Fayed AA. Intravitreal bevacizumab alone or combined with macular laser for treatment of diabetic macular edema. Egypt Retina J. 2017; 4: 37-42.
20. Adelman R, Parnes A, Michalewska Z, Parolini B, Boscher C, Ducournau D. Strategy for the management of diabetic macular edema: The European Vitreo retinal Society Macular Edema Study. Biomed Res Int. 2015; 2015: 1-9.

21. Do DV, Nguyen QD, Khwaja AA, Channa R, Sepah YJ, Sophie R, et al. Ranibizumab for edema of the macula in diabetes study: 3-year outcomes and the need for prolonged frequent treatment. JAMA Ophthalmol 2013; 131: 139-145.

\section{Authors' Designation and Contribution}

Mahtab Alam Khanzada: Associate Professor: Concepts, Design, Manuscript preparation.

Munawar Ahmed: Associate Professor: Data analysis, Statistical analysis, Manuscript editing.

Azfar Ahmed Mirza: Assistant Professor: Literature search.

Ghazi Khan Mari: Assistant Professor: Data acquisition.

Muhammad Arshad Mahmood; Professor: Manuscript review.

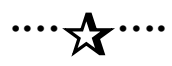

